\title{
Sex hormone binding globulin, free estradiol index, and lipid profiles in girls with precocious puberty
}

\author{
Hyun-Wook Chae, MD', \\ Ah-Reum Kwon, MD', \\ Duk-Hee Kim, MD, PhD', \\ Ho-Seong Kim, MD, PhD' \\ ${ }^{1}$ Department of Pediatrics, Yonsei \\ University College of Medicine, \\ Seoul, ${ }^{2}$ Sowha Children's Hospital, \\ Seoul, Korea
}

\begin{abstract}
Purpose: Sex hormone-binding globulin (SHBG) modulates the availability of biologically active free sex hormones. The regulatory role of SHBG might be important in the relationship between hormone levels and the modification of lipid profiles in girls with precocious puberty. However, few studies have evaluated the relationship of SHBG, free estradiol index (FEI), and lipid levels in these girls.

Methods: One hundred and nine girls less than 8 years of age with pubertal development were enrolled. FEl was calculated with SHBG and estradiol (E2). We analyzed SHBG between peak luteinizing hormone (LH) $\geq 5$ (IU/L) (group 1) and $\mathrm{LH}<5$ (IU/L) (group 2) through a gonadotropin releasing hormone stimulation test.

Results: Body mass index (BMI) standard deviation score (SDS) was higher in group 2 than in group $1(P=0.004)$. Serum SHBG levels did not differ and FEl was not higher in group $1(P=0.122)$. Serum cholesterol, $\mathrm{HDL}$, and LDL did not differ; however, triglyceride levels were higher in group $2(P=0.023)$. SHBG was negatively correlated with bone age advancement, BMI, BMI SDS, and FEl, and was positively correlated with HDL. However, SHBG was not correlated with E2 or peak LH.

Conclusion: Serum SHBG itself might not be associated with precocious puberty in girls, but it might be related to BMI and lipid profiles. Further studies are needed to reveal the relationship between sex hormone and obesity in girls with precocious puberty.
\end{abstract}

Keywords: Sex hormone-binding globulin, Estradiol, Lipid, Precocious puberty

\section{Introduction}

Sex hormone-binding globulin (SHBG) is a glycoprotein that binds to sex hormones such as androgens and estrogens ${ }^{1)}$. Most of SHBG bind over 97\% of testosterone and estradiol (E2) ${ }^{2}$. When checking serum E2, a total level includes free and bound forms. A free estradiol index (FEI) expresses the ratio of E2 to SHBG and can be used to summarize the activity of free forms of E2. Thus, the concentration of SHBG is a major constituent regulating distribution of sex hormones between the protein-bound and free states ${ }^{3)}$, and the bioavailability of sex hormones is influenced by the level of $\mathrm{SHBG}^{4)}$.

It is known that various conditions with low SHBG include hypothyroidism, Cushing syndrome, polycystic ovary syndrome, diabetes and obesity ${ }^{5}$. The level of SHBG was high in girls with premature thelarche ${ }^{6)}$. Low levels of SHBG at menarche have been reported in girls with constitutionally delayed puberty ${ }^{7}$. The oral contraceptive containing ethinylestradiol administration increases SHBG level ${ }^{8)}$. Early childhood is characterized by high levels of SHBG with a gradual decline as puberty approaches ${ }^{9,10)}$.

SHBG might have important role in the progress of precocious puberty, but few studies evaluated the relationship in girls with precocious puberty. The first aim of this study was to evaluate the association between sex hormones and SHBG in girls with idiopathic central

Tel: $+82-2-2228-2069$

Fax: $+82-2-393-9118$

E-mail:kimho@yuhs.ac 
precocious puberty. We compared the difference of SHBG between peak luteinizing hormone $(\mathrm{LH}) \geq 5$ group and $\mathrm{LH}$ $<5$ group through gonadotropin releasing hormone $(\mathrm{GnRH})$ stimulation test. Second, we investigated the relationship between weight, lipid profiles and SHBG.

\section{Materials and methods}

A total of 109 girls with pubertal development aged under 8 years at Gangnam Severance Hospital were included in this study from January 2010 to August 2011. We reviewed the records of all the girls with premature sexual development who underwent GnRH stimulation tests retrospectively. The inclusion criteria for this study were objective breast budding before the age of 8 years, more than Tanner stage 2 by one pediatric endocrinologist and advanced bone age over the chronological age. The subjects with an identified etiology, such as brain tumor or hypoxic damage, were excluded.

Height was measured by a stadiometer (Harpenden Ltd., Crymych, UK) to the nearest $0.1 \mathrm{~cm}$. Weight was measured on a digital scale with a precision of $0.1 \mathrm{~kg}$ (SECA, model 707). Body mass index (BMI) was calculated as weight (kilograms) divided by height (meters) squared.

The hypothalamic-pituitary-gonadal axis was investigated by GnRH stimulation test. Basal serum samples were obtained prior to the GnRH (100 $\mu$ g Relefact; Sanofi-Aventis, Frankfurt, Germany) injection. Post stimulation samples for measurements of LH, FSH, and E2 levels were acquired at 30, 60, 90 and 120 minutes after the GnRH injection. Serum LH and FSH levels were measured by immunoradiometric assay (IRMA) with analytical sensitivity of 0.2 IU/L (BioSource, Nivelles, Belgium). The E2 levels were determined by radioimmunoassay with analytical sensitivity of $5 \mathrm{pg} / \mathrm{mL}$ (RIA; Coat-A-Count, Diagnostic Products, Los Angeles, CA, USA). SHBG was determined by a immunofluorescence assay (Delfia, Wallac Oy,
Turku, Finland). FEI was calculated by dividing the serum E2 level by the serum SHBG level and multiplying by 100. A peak $\mathrm{LH}$ of at least $5 \mathrm{IU} / \mathrm{L}$ was used as the cutoff criteria for pubertal response through the GnRH stimulation test.

Data were analyzed by the SAS 9.1 (SAS Institute Inc., Cary, NC, USA). Two sample t test or Mann-Whitney $U$ test were performed to compare the clinical parameters of the subjects in between groups. Pearson correlation for SHBG and peak LH was examined. To determine significant association with pubertal response, linear regression was performed with univariate and multivariate analysis. Significance was determined as $P<0.05$.

This study was approved by the Institutional Review Board of Yonsei University Gangnam Severance Hospital (IRB number 3-2011-0314). Written informed consent was exempted from all subjects as well as their parents.

\section{Results}

Baseline patient characteristics between peak $\mathrm{LH} \geq 5$ (group 1) and $\mathrm{LH}<5$ (group 2) through GnRH stimulation tests are shown in Table 1. BMI standard deviation score (SDS) was higher in group 2 than group $1(P=0.004)$. Serum E2 and SHBG levels were not different in both group. FEI were not higher in group $1(P=0.122)$. Serum cholesterol, high-density lipoprotein (HDL) and low-density lipoprotein (LDL) were not different, however, triglycerides levels were higher in group $2(P=0.023)$.

From the analysis of Pearson correlation in group 1, SHBG was negatively correlated with bone age (BA) advancement, BMI, BMI SDS, FEI, and positively with HDL (Table 2). However, SHBG was not correlated with E2 and peak LH.

Table 3 shows association between peak LH and measurements in group 1 through multiple regression analysis. BA, BMI SDS, FEI, cholesterol, triglycerides and SHBG did not show significant correlation with peak LH. We performed multivariate

Table 1. Baseline characteristics of patients according to peak LH level through a GnRH stimulation test

\begin{tabular}{|c|c|c|c|c|}
\hline Characteristic & $\mathrm{LH} \geq 5(\mathrm{IU} / \mathrm{L}) \quad(\mathrm{n}=54)$ & $\mathrm{LH}<5(\mathrm{IU} / \mathrm{L})(\mathrm{n}=55)$ & Total $(n=109)$ & $P$-value \\
\hline CA (yr) & $8.1 \pm 1.3$ & $8.2 \pm 1.4$ & $8.1 \pm 1.3$ & 0.541 \\
\hline$B A(y r)$ & $9.1 \pm 1.6$ & $9.0 \pm 1.5$ & $9.1 \pm 1.7$ & 0.324 \\
\hline $\mathrm{BA}-\mathrm{CA}(\mathrm{yr})$ & $0.99 \pm 0.69$ & $0.94 \pm 0.70$ & $0.97 \pm 0.69$ & 0.734 \\
\hline BMI SDS & $0.17 \pm 0.78$ & $0.77 \pm 1.33$ & $0.45 \pm 0.56$ & 0.004 \\
\hline Peak LH (IU/L) & $12.4 \pm 6.4$ & $2.9 \pm 2.1$ & $8.9 \pm 5.8$ & 0.001 \\
\hline E2 (pg/mL) & $19.0 \pm 15.7$ & $14.2 \pm 9.6$ & $16.8 \pm 12.1$ & 0.056 \\
\hline $\mathrm{FEl}(\mathrm{pmol} / \mathrm{L})$ & $27.9 \pm 24.8$ & $21.5 \pm 20.0$ & $24.8 \pm 22.9$ & 0.122 \\
\hline SHBG (nmol/L) & $85.9 \pm 30.6$ & $80.9 \pm 37.8$ & $83.2 \pm 36.4$ & 0.428 \\
\hline IGF-1( $\mu \mathrm{g} / \mathrm{L})$ & $258.0 \pm 92.9$ & $206.6 \pm 64.0$ & $227.6 \pm 88.7$ & 0.002 \\
\hline Cholesterol (mg/dL) & $158.3 \pm 23.6$ & $152.8 \pm 17.8$ & $155.8 \pm 21.9$ & 0.203 \\
\hline $\mathrm{HDL}(\mathrm{mg} / \mathrm{dL})$ & $53.0 \pm 10.0$ & $49.7 \pm 10.1$ & $51.5 \pm 10.1$ & 0.082 \\
\hline LDL (mg/dL) & $88.4 \pm 20.2$ & $81.8 \pm 15.1$ & $84.9 \pm 17.8$ & 0.104 \\
\hline Triglycerides (mg/dL) & $85.6 \pm 42.7$ & $112.2 \pm 72.0$ & $101.1 \pm 61.9$ & 0.023 \\
\hline
\end{tabular}

Values are presented as mean \pm standard deviation.

LH, luteinizing hormone; GnRH, gonadotropin releasing hormone; CA, chronologic age; BA, bone age; BMI, body mass index; SDS, standard deviation score; E2, estradiol; FEl, free estradiol index; SHBG, sex hormone binding globulin; IGF-1, insulin like growth factor 1; $\mathrm{HDL}$, high-density lipoprotein; LDL, low-density lipoprotein. 
logistic regression of variables associated with peak LH and calculated odds ratio (Table 4). BA advancement, BMI SDS, cholesterol, triglycerides and SHBG did not show significant results.

\section{Discussion}

\section{Association between sex hormones and SHBG in girls with precocious puberty}

In the present study, the SHBG levels were not higher in pubertal response group than nonpubertal response group, and SHBG did not show significant correlation with peak LH. There are various studies about conditions influencing levels of SHBG. It decreases with high levels of insulin, growth hormone, insulin-like growth factor 1 , androgens and prolactin ${ }^{5,11)}$. High estrogen and thyroxine cause it to increase ${ }^{8)}$. From this point of view, it seemed to be appropriate that the levels of SHBG might increase in girls with precocious puberty. However, Sorensen et al. ${ }^{4)}$ showed that 25 girls with idiopathic central precocious puberty had lower levels of SHBG at diagnosis compared with controls. The study showed that the low SHBG levels decreased further during the 24-month with GnRH agonist treatment for central precocious puberty, and no tendency toward normalization was observed ${ }^{4)}$.

The levels of SHBG in girls with central precocious puberty are not uniform like this. It is unclear how SHBG is associated with sex hormones in precocious puberty. We can consider various factors affecting SHBG levels in girls during puberty. First, alteration of the androgen-estrogen balance during precocious pubertal development can affect the levels of $\mathrm{SHBG}^{12)}$. The subtle decreases in plasma SHBG levels during puberty have a perceptible effect on the androgen-estrogen balance ${ }^{5)}$. Second, changes in body mass and composition are

Table 2. Pearson correlation for SHBG and peak LH peak in pubertal response group

\begin{tabular}{|c|c|c|c|c|}
\hline & \multicolumn{2}{|c|}{ SHBG } & \multicolumn{2}{|c|}{ Peak LH } \\
\hline & $\begin{array}{l}\text { Correlation } \\
\text { coefficient }(r)\end{array}$ & $P$-value & $\begin{array}{l}\text { Correlation } \\
\text { coefficient }(r)\end{array}$ & $P$-value \\
\hline$\overline{S H B G}$ & & & -0.132 & 0.161 \\
\hline $\mathrm{BA}-\mathrm{CA}$ & -0.231 & 0.014 & 0.147 & 0.123 \\
\hline Weight & -0.396 & 0.002 & 0.274 & 0.036 \\
\hline BMI & -0.291 & 0.025 & 0.228 & 0.083 \\
\hline BMI SDS & -0.257 & 0.049 & -0.073 & 0.442 \\
\hline E2 & -0.205 & 0.119 & 0.368 & 0.001 \\
\hline FEI & -0.538 & 0.001 & 0.309 & 0.001 \\
\hline Cholesterol & 0.149 & 0.120 & 0.168 & 0.079 \\
\hline LDL & 0.181 & 0.208 & 0.120 & 0.246 \\
\hline $\mathrm{HDL}$ & 0.260 & 0.010 & 0.128 & 0.211 \\
\hline Triglycerides & -0.073 & 0.475 & -0.132 & 0.195 \\
\hline
\end{tabular}

SHBG, sex hormone binding globulin; LH, luteinizing hormone; $\mathrm{BA}$, bone age; CA, chronologic age; BMI, body mass index; SDS, standard deviation score; E2, estradiol; FEl, free estradiol index; LDL, low-density lipoprotein; HDL, high-density lipoprotein. also major determinants of plasma SHBG levels, particularly in girls during puberty ${ }^{13,14)}$. It might be confounding factors that BMI SDS was higher in nonpubertal response group in this study.

\section{Association between weight, lipid profiles and SHBG in pubertal response group}

SHBG was negatively correlated with weight, BMI, BMI SDS, and positively with HDL in pubertal response group. Our results coincide with previous reports. In women, low circulating SHBG was found to be associated with an increased accumulation of abdominal fat and body fat mass ${ }^{15,16)}$. There are various studies that plasma level of SHBG has emerged as one of the most important correlates of obesity-related metabolic complications ${ }^{17)}$. Reduced SHBG level in women has also been associated with an adverse blood lipid profile, including reduced HDL cholesterol ${ }^{18,19)}$. Furthermore, low circulating SHBG was associated with glucose intolerance, insulin resistance, as well as with the risk of cardiovascular disease and type 2 diabetes in women ${ }^{18,20)}$. The observed correlations might support the hypothesis that SHBG might have roles associated with obesity related risk factors in girls with precocious puberty, however, few studies evaluated the relationship.

This study has several limitations. First, the present study is the just cross-sectional study with small sample size. The total number of patients was 109 , and the number of pubertal response group was only 54. Future studies of the effects of SHBG on the development and progression of precocious

Table 3. Multiple regression analysis: Associations between peak LH and measurements in the pubertal response group

\begin{tabular}{lccc}
\hline & Standardized coefficients B & $t$ & $P$-value \\
\hline BA & 0.058 & 0.366 & 0.716 \\
BMI SDS & 0.059 & 0.279 & 0.782 \\
FEl & -0.299 & -1.594 & 0.119 \\
Cholesterol & -0.187 & -1.100 & 0.278 \\
Triglycerides & -0.118 & -0.641 & 0.525 \\
SHBG & -0.028 & -0.134 & 0.894 \\
\hline
\end{tabular}

$\mathrm{LH}$, luteinizing hormone; $\mathrm{BA}$, bone age; $\mathrm{BMI}$, body mass index; SDS, standard deviation score; FEl, free estradiol index; SHBG, sex hormone binding globulin.

Table 4. Multivariate logistic regression of variables associated with peak $\mathrm{LH}$

\begin{tabular}{lccc}
\hline Variable & Odds ratio & $95 \% \mathrm{Cl}$ & $P$-value \\
\hline SHBG & 0.993 & $0.98-1.01$ & 0.903 \\
BA-CA & 0.892 & $0.36-2.24$ & 0.812 \\
BMI SDS & 3.337 & $0.21-52.40$ & 0.393 \\
Cholesterol & 1.018 & $0.95-1.07$ & 0.746 \\
Triglycerides & 0.991 & $0.97-1.00$ & 0.117 \\
\hline L
\end{tabular}

$\mathrm{LH}$, luteinizing hormone; $\mathrm{Cl}$, confidence interval; SHBG, sex hormone binding globulin; BA, bone age; CA, chronologic age; BMI, body mass index; SDS, standard deviation score. 
puberty should include large data through longitudinal study. Second, our data did not include other associated factors, such as insulin. Insulin is a potent inhibitor of SHBG, and SHBG might be a marker of hyperinsulinemia and insulin resistance ${ }^{5,21)}$. More accurate analysis including various hormones should be needed to identify the relationship between precocious puberty and obesity.

In conclusion, serum SHBG itself might not be associated with precocious puberty in girls, but it might be related with weight, BMI and lipid profiles. Large number of longitudinal studies are needed to reveal relationship between sex hormone and obesity in precocious puberty.

\section{Conflict of interest}

No potential conflict of interest relevant to this article was reported.

\section{References}

1. Sodergard R, Backstrom T, Shanbhag V, Carstensen H. Calculation of free and bound fractions of testosterone and estradiol-17 beta to human plasma proteins at body temperature. J Steroid Biochem 1982;16:801-10.

2. Rinaldi S, Geay A, Dechaud H, Biessy C, ZeleniuchJacquotte A, Akhmedkhanov A, et al. Validity of free testosterone and free estradiol determinations in serum samples from postmenopausal women by theoretical calculations. Cancer Epidemiol Biomarkers Prev 2002;11(10 Pt 1):1065-71.

3. Selby C. Sex hormone binding globulin: origin, function and clinical significance. Ann Clin Biochem 1990;27(Pt 6):532-41

4. Sørensen K, Andersson AM, Skakkebaek NE, Juul A. Serum sex hormone-binding globulin levels in healthy children and girls with precocious puberty before and during gonadotropin-releasing hormone agonist treatment. J Clin Endocrinol Metab 2007;92:3189-96.

5. Pugeat M, Cousin P, Baret C, Lejeune H, Forest MG. Sex hormone-binding globulin during puberty in normal and hyperandrogenic girls. J Pediatr Endocrinol Metab 2000;13 Suppl 5:1277-9.

6. Belgorosky A, Chaler E, Rivarola MA. High serum sex hormone-binding globulin (SHBG) in premature thelarche. Clin Endocrinol (Oxf) 1992;37:203-6.

7. Błogowska A, Rzepka-Gorska I, Zołtowski S. Sex features at menarche in relation to gonadotropin, estradiol and sex hormone-binding globulin concentrations in girls with constitutional delay of puberty. Preliminary report. Gynecol Endocrinol 2005;20:270-3.

8. Wiegratz I, Jung-Hoffmann C, Kuhl H. Effect of two oral contraceptives containing ethinylestradiol and gestodene or norgestimate upon androgen parameters and serum binding proteins. Contraception 1995;51:341-6.

9. Galloway PJ, Donaldson MD, Wallace AM. Sex hormone binding globulin concentration as a prepubertal marker for hyperinsulinaemia in obesity. Arch Dis Child 2001;85:48991.

10. Ibanez L, Ong K, de Zegher F, Marcos MV, del Rio L, Dunger DB. Fat distribution in non-obese girls with and without precocious pubarche: central adiposity related to insulinaemia and androgenaemia from prepuberty to postmenarche. Clin Endocrinol (Oxf) 2003;58:372-9.

11. Sagodi L, Barkai L, Tombacz A, Vamosi I. Hyperinsulinemia, insulin-like growth factor-I, insulin-like growth factorbinding protein-1, and sex-hormone binding-globulin in prepubertal and pubertal girls with premature adrenarche. Orv Hetil 2003;144:67-72.

12. Mauras N, Rogol AD, Haymond MW, Veldhuis JD. Sex steroids, growth hormone, insulin-like growth factor-1: neuroendocrine and metabolic regulation in puberty. Horm Res 1996;45:74-80.

13. Hammond GL. Diverse roles for sex hormone-binding globulin in reproduction. Biol Reprod 2011;85:431-41.

14. Hammond GL, Wu TS, Simard M. Evolving utility of sex hormone-binding globulin measurements in clinical medicine. Curr Opin Endocrinol Diabetes Obes 2012;19:183-9.

15. Haffner SM, Katz MS, Dunn JF. Increased upper body and overall adiposity is associated with decreased sex hormone binding globulin in postmenopausal women. Int J Obes 1991;15:471-8.

16. Evans DJ, Hoffmann RG, Kalkhoff RK, Kissebah AH. Relationship of androgenic activity to body fat topography, fat cell morphology, and metabolic aberrations in premenopausal women. J Clin Endocrinol Metab 1983;57:304-10.

17. Tchernof A, Despres JP. Sex steroid hormones, sex hormone-binding globulin, and obesity in men and women. Horm Metab Res 2000;32:526-36.

18. Pugeat M, Moulin P, Cousin P, Fimbel S, Nicolas MH, Crave $\mathrm{JC}$, et al. Interrelations between sex hormone-binding globulin (SHBG), plasma lipoproteins and cardiovascular risk. J Steroid Biochem Mol Biol 1995;53:567-72.

19. Soler JT, Folsom AR, Kaye SA, Prineas RJ. Associations of abdominal adiposity, fasting insulin, sex hormone binding globulin, and estrone with lipids and lipoproteins in postmenopausal women. Atherosclerosis 1989;79:21-7.

20. Haffner SM, Valdez RA, Morales PA, Hazuda HP, Stern MP. Decreased sex hormone-binding globulin predicts noninsulin-dependent diabetes mellitus in women but not in men. J Clin Endocrinol Metab 1993;77:56-60.

21. Nestler JE, Powers LP, Matt DW, Steingold KA, Plymate SR, Rittmaster RS, et al. A direct effect of hyperinsulinemia on serum sex hormone-binding globulin levels in obese women with the polycystic ovary syndrome. J Clin Endocrinol Metab 1991;72:83-9. 